\title{
Does Ozone-Water Complex Produce Additional OH Radicals in the Atmosphere?
}

\author{
Bing Jin, ${ }^{\dagger}$ Man-Nung Su, ${ }^{\dagger}$ and Jim Jr-Min Lin ${ }^{*}, \dagger, \S$ \\ ${ }^{\dagger}$ Institute of Atomic and Molecular Sciences, Academia Sinica, Taipei 10617, Taiwan \\ ${ }^{\ddagger}$ Department of Chemistry, National Taiwan University, Taipei 10617, Taiwan \\ ${ }^{\S}$ Department of Applied Chemistry, National Chiao Tung University, Hsinchu 30010, Taiwan

\section{Supporting Information}

ABSTRACT: Ozone-water complex has been thought to play a role in producing atmospheric $\mathrm{OH}$ radicals through its photolysis. Here, we re-examined the absorption cross-section of the ozone-water complex with a new method to tell whether the above speculation is valid. With argon solvation and photoionization by tunable vacuum ultraviolet light, we were able to selectively probe the ozone-water $1: 1$ complex. The measured cross-section of the complex is only similar to the sum of the cross-sections of ozone and water monomers at 157.6, 248.4, and $308.4 \mathrm{~nm}$. In addition, we did not observe any absorption of the complex at $351.8 \mathrm{~nm}$. The results indicate that the $\mathrm{OH}$ production through the photolysis of the ozonewater complex is much slower than previously thought.

\section{INTRODUCTION}

Hydroxyl radicals $(\mathrm{OH})$ are the most important oxidant in the atmosphere. They are often called the detergent of the atmosphere because they react with major atmospheric pollutants. In addition, $\mathrm{OH}$ chemistry is linked with a number of important atmospheric species, like volatile organic compounds, $\mathrm{CO}$ and $\mathrm{NO}_{x}$, and leads to ozone and aerosol formation. The primary source of atmospheric $\mathrm{OH}$ radicals is through the ultraviolet (UV) photolysis of ozone and subsequent reaction with water (eqs 1 and 2 ).

$$
\begin{aligned}
& \mathrm{O}_{3}+h \nu \rightarrow \mathrm{O}\left({ }^{1} \mathrm{D}\right)+\mathrm{O}_{2} \\
& \mathrm{O}\left({ }^{1} \mathrm{D}\right)+\mathrm{H}_{2} \mathrm{O} \rightarrow 2 \mathrm{OH}
\end{aligned}
$$

Recently, there has been growing interest in various unconventional photochemical sources of atmospheric $\mathrm{OH}$ radicals, ${ }^{1-5}$ arising from the need to explain the discrepancy between measurements and models. ${ }^{6-9}$ Among them, the photolysis of ozone-water complex has been speculated to be an additional $\mathrm{OH}$ source in the troposphere. ${ }^{10-12}$

$$
\mathrm{O}_{3} \cdot \mathrm{H}_{2} \mathrm{O}+h \nu \rightarrow 2 \mathrm{OH}+\mathrm{O}_{2}
$$

Frost et al. ${ }^{10}$ suggested this source (eq 3 ) is significant at the Earth's surface with a contribution up to $15 \%$ of the available $\mathrm{OH}$. Given the importance of water in atmospheric and environmental chemistry ${ }^{10-15}$ and that not all $\mathrm{OH}$ sources have been well quantified yet, ${ }^{2,6-9}$ it would be important to reexamine the validity of this contribution. The main idea of this unconventional $\mathrm{OH}$ source is that the long-wavelength absorption of ozone may be enhanced upon being complexed with water. $^{10-12,16}$ This makes the process of eq 3 become

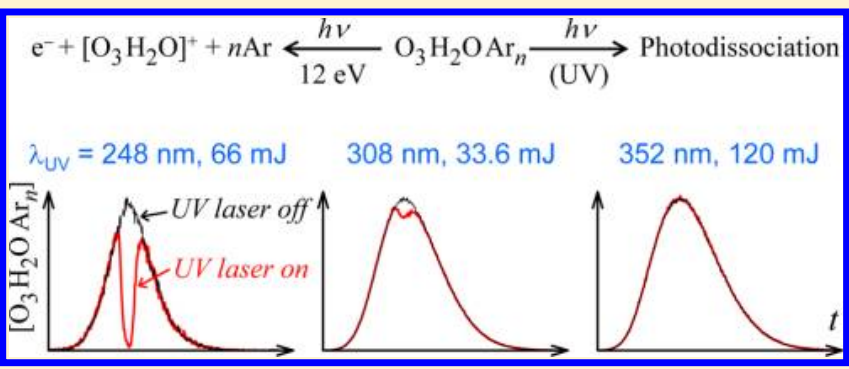

important in comparison with the conventional $\mathrm{OH}$ source (eqs 1 and 2) because the stratospheric ozone layer absorbs most of the UV light at wavelengths $(\lambda)$ shorter than $300 \mathrm{~nm}$ and this self-shielding effect limits the photolysis rates of low altitude ozone, especially at large solar zenith angles. As a result, the red-shifted absorption of the ozone-water complex would have a greater spectral overlap with the incoming solar flux and may produce a significant amount of $\mathrm{OH}$ radicals despite its low concentration. Furthermore, there is experimental evidence to support this $\mathrm{OH}$ source (eq 3) in which Hurwitz and Naaman ${ }^{16}$ reported detection of $\mathrm{OH}$ radicals in a molecular beam containing ozone and water after UV laser photolysis. They claimed that the absorption of ozone at $355 \mathrm{~nm}$ is enhanced by 2 orders of magnitude when ozone is complexed with water and further suggested that the Hartley absorption band of ozone will be red-shifted when ozone interacts with a single water molecule. Consequently, Frost et al. ${ }^{10}$ estimated the atmospheric $\mathrm{OH}$ production rate of eq 3 and concluded that it can be significant. ${ }^{10-12}$

However, it is difficult to either support or refute the above speculation. The contribution of the complex photolysis (eq 3) to the atmospheric $\mathrm{OH}$ production would depend on the following factors: ${ }^{17}$ (i) the concentration of the ozone-water complex in the atmosphere, (ii) its atmospheric photolysis rate, and (iii) the quantum yield of the $\mathrm{OH}$ production. Because the binding energy of the ozone-water complex is small, its concentration would be low $\left(\sim 2 \times 10^{6}-4 \times 10^{7} \mathrm{~cm}^{-3}\right)^{10}$

Received: October 4, 2012

Revised: November 20, 2012

Published: November 20, 2012 
compared to the typical concentrations of ozone $\left(\sim 8 \times 10^{11}\right.$ $\left.\mathrm{cm}^{-3}\right)$ and water $\left(\sim 4 \times 10^{17} \mathrm{~cm}^{-3}\right)$ near the earth's surface. ${ }^{10}$ However, as mentioned above, the photolysis rate may be greatly enhanced if the complex absorption spectrum is redshifted. Regarding the third factor, the $\mathrm{OH}$ quantum yield of eq 3 is difficult to know, but it has an upper limit of 2. Frankly speaking, it is a challenge to determine any one of the above 3 factors unambiguously. In this article, we examine the second factor through measuring the complex absorption cross-section, which is directly related to its photolysis rate.

There have been a number of investigations on the ozonewater complex and its photochemistry. ${ }^{16-23}$ Gillies et al. ${ }^{18}$ studied the high-resolution microwave spectrum of the ozonewater complex. Their result indicates that the complex has a $C_{s}$ symmetry with water and that the center oxygen atom of ozone lies in the symmetry plane. On the basis of the determined complex structure, Gillies et al. ${ }^{18}$ reported the calculated binding energy to be $0.7 \mathrm{kcal} \mathrm{mol}^{-1}$ at the MP4(SDTQ)/6$31 \mathrm{G}(\mathrm{d}, \mathrm{p})$ level of theory after correction of basis set superposition error (BSSE), while the value of $2.4 \mathrm{kcal} \mathrm{mol}^{-1}$ was obtained at the same level of theory without BSSE correction. Schriver et al. ${ }^{19}$ prepared a few ozone-water complexes with various $\mathrm{O}_{3}$ and $\mathrm{H}_{2} \mathrm{O}$ compositions, such as 1:1, $2: 1$, and $1: 2$, in an argon matrix and studied their infrared absorption spectra. From the frequency shift of the water moiety, they postulated that the $\mathrm{O}_{3} \cdot \mathrm{H}_{2} \mathrm{O} \quad 1: 1$ complex has a binding energy of less than $1 \mathrm{kcal} \mathrm{mol}^{-1}{ }^{19}$ Recently, Tsuge et al. ${ }^{17}$ studied the ozone-water complex with neon matrixisolation infrared spectroscopy and ab initio calculations. Their calculation gives a binding energy of $1.9 \mathrm{kcal} \mathrm{mol}^{-1}$ at $\operatorname{CCSD}(\mathrm{T}) / 6-311++\mathrm{G}(3 \mathrm{df}, 3 \mathrm{pd}) / / \mathrm{CCSD} / 6-311++\mathrm{G}(\mathrm{d}, \mathrm{p})$ level of theory (with BSSE correction), and they estimated about $4 \times$ $10^{-5}$ of tropospheric ozone would exist as the water complex form. ${ }^{17}$ In addition, Tachikawa et al. ${ }^{20}$ reported their theoretical binding energy to be $1.5 \mathrm{kcal} \mathrm{mol}^{-1}$ at the level of QCISD(T)/ 6-311++G(3df,3pd)//QCISD/6-311++G(d,p) after BSSE correction.

For the UV photolysis of the ozone-water complex in the gas phase, King et al. ${ }^{21}$ investigated the dynamics of the $\mathrm{OH}$ production from the complex photolysis at 266 and $281.5 \mathrm{~nm}$ with laser induced fluorescence (LIF) detection and isotope labeling. Hurwitz and Naaman ${ }^{16}$ extended the investigation to $355 \mathrm{~nm}$ also with LIF detection and suggested a red-shifted spectrum for the Hartley band of ozone after being complexed with water. Very recently, Axson et al. ${ }^{22}$ attempted to probe the absorption of the ozone-water complex by measuring the spectrum of a humidified ozone gas (90\% relative humidity) with a highly sensitive cavity-enhanced method, but because the concentration ratio of the complex to the ozone monomer was very low in their sample, they could not observe any change in absorption due to the complex.

Buckley and Birks ${ }^{23}$ have investigated the visible-light photolysis of ozone/water mixtures at ambient temperature and concluded that the visible-light photolysis to form $\mathrm{OH}$ radicals may be ruled out as an atmospherically significant process, but they offered no information regarding the UV photolysis.

To tell whether the speculation by Frost et al. ${ }^{10-12}$ is valid or not, we chose to investigate the absorption cross-section of the ozone-water complex. Recently, our laboratory developed a method $^{24-28}$ that is able to measure the absorption crosssection of an unstable species. One great advantage of our method is that it does not require the knowledge of concentrations of the absorbing species. Simply speaking, we detected the target species selectively in a molecular beam by mass spectrometry; before the molecule reached the detector, we crossed the molecular beam with an intense laser beam; if the molecule absorbs a photon and dissociates, its number reaching the detector would be reduced. By comparing this laser depletion signal with that of a reference molecule having a known cross-section, we can quantify the cross-section of the target species. This method has been proven to be of high specificity and good accuracy. ${ }^{24-28}$

\section{EXPERIMENTAL SECTION}

The experimental method ${ }^{24-28}$ and apparatus ${ }^{29,30}$ have been described elsewhere. Thus, only the relevant details are given here. An experimental schematic is shown in Supplementary Figure S1.

To generate a molecular beam containing ozone-water complexes, we used two pulsed valves (Even-Lavie valve ${ }^{31,32}$ ), one for ozone/argon gas and the other for water/argon gas. Both gases were mixed together (after their own pulsed valves) in a small volume of $\sim 1.5 \mathrm{~mm}^{3}$ and expanded into a vacuum chamber to form a molecular beam. The reason to use two pulsed valves was that the ozone/water mixture is quite corrosive. The steel spring of the pulsed valve became rusted after being exposed to ozone/water mixture in an earlier (single valve) design and caused the pulsed valve to malfunction. The delay time between two pulsed valves was adjusted to optimize the intensity of the desired ozone-water complex. The nozzle temperature was kept at about $302 \mathrm{~K}$. The backing pressures were 4.1 and 4.8 bar for the ozone and water pulsed valves, respectively.

The molecular beam size was defined by a slit $(4 \mathrm{~mm}$ wide $\times$ $0.5 \mathrm{~mm}$ height) before it was intersected by a laser beam (6-10 $\mathrm{mm}$ wide $\times 0.5-2 \mathrm{~mm}$ height, depending on the wavelength), which was $280 \mathrm{~mm}$ away from the molecular beam nozzle; the molecular beam was photoionized by a vacuum UV photon beam $(1 \mathrm{~mm} \times 1 \mathrm{~mm}$, from synchrotron radiation, Beamline $21 \mathrm{~A} 1$ of the Taiwan Light Source), ${ }^{29,30}$ which was another 100 $\mathrm{mm}$ downstream from the laser crossing point. The ions were mass-selected with a quadrupole mass filter and detected with a Daly detector, which was coupled to a multichannel scalar to perform ion counting. In this experiment, the molecular beam, laser beam, and synchrotron-radiation photon beam were in the same horizontal plane.

Both pulsed valves were operated at $100 \mathrm{~Hz}$ repetition rate, and the photolysis laser was fired at $50 \mathrm{~Hz}$. Thus, half of the molecular beam pulses did not interact with the laser beam and served as a reference signal. The laser delay time was adjusted such that the laser pulse overlapped with the peak of the molecular beam pulse. Because of the two-valve design, ozone, water, and their complexes did not have the same arrival time profiles (because only a certain portion of the gas pulse had good mixing, which is required for complex formation), such that the photolysis laser was fired at different delay times when detecting different species. In all the presented data, the time zero was set to the time of the photolysis laser pulse.

Under our experimental conditions, the photodepletion process (absorption and dissociation) can be described as ${ }^{24-28}$

$$
\ln \left(\frac{N}{N_{0}}\right)=-I \sigma \phi
$$


where $N_{0}$ and $N$ are the numbers of the molecules in the laser interaction volume before and after laser irradiation, respectively; $I$ is the laser fluence in number of photons per unit area; $\sigma$ is the absorption cross-section, and $\phi$ is the dissociation quantum yield. After absorbing a UV photon, the molecules in this study $\left(\mathrm{O}_{3}, \mathrm{H}_{2} \mathrm{O}\right.$, and $\left.\mathrm{Cl}_{2}\right)$ are excited to repulsive states or states well above their dissociation thresholds, leading to complete dissociation $(\phi=1)$. For a van der Waals cluster, the dissociation quantum yield would also be unity because the photon energy is much greater than the cluster binding energy (our detection time scale was in the order of $10^{-4}$ seconds). By comparing the laser depletion signal to that of a reference molecule having a known cross-section, we can obtain the cross-section of the target species.

\section{RESULTS AND DISCUSSION}

Detecting the Ozone-Water Complex. The ozonewater complexes were detected with soft ionization using tunable vacuum UV photons from synchrotron radiation. Figure 1 shows the photoionization efficiency (PIE) spectrum

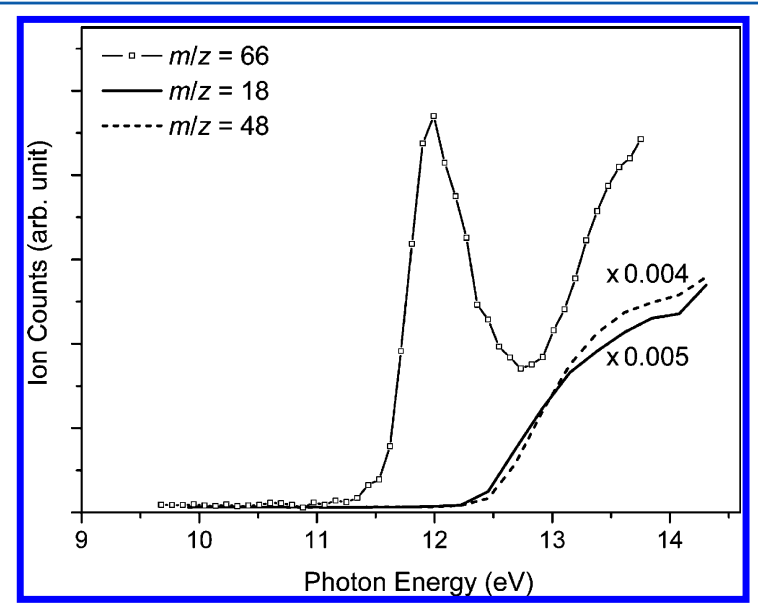

Figure 1. Photoionization efficiency (PIE) spectra of ozone $(\mathrm{m} / \mathrm{z}=$ $48)$, water $(m / z=18)$, and an ozone-water complex detected at $m / z$ $=66$. The ionizing photons were from an undulator beamline of synchrotron radiation. The spectral width is mostly due to the energy resolution of the beamline. The intensities of ozone and water ions have been multiplied by factors of 0.004 and 0.005 , respectively.

of a complex detected at $m / z=66\left(\mathrm{O}_{3} \mathrm{H}_{2} \mathrm{O}\right)^{+}$. The PIE spectra of ozone and water are also shown for comparison. The most pronounced feature in Figure 1 is a strong resonance peak in the PIE spectrum of $m / z=66$ at about $12 \mathrm{eV}$. A similar resonance has been observed in the case of water-argon complexes. ${ }^{33}$ Analogous to ref 33, the resonance peak in Figure 1 indicates that the ozone-water complex observed at $\mathrm{m} / \mathrm{z}=$ 66 is solvated by Ar atoms. After photoexcitation, the Ar exciton (excited state of Ar) transfers its electronic energy to the ozone-water solute and causes ionization of the solute; evaporation of Ar solvent carries away the excess energy of the ionization process and stabilizes the ionic solute. ${ }^{33}$ It is noteworthy that the Ar resonance energy of $12 \mathrm{eV}$ is lower than the ionization energies (IE) of $\mathrm{H}_{2} \mathrm{O}$ and $\mathrm{O}_{3}$ monomers (12.6 and $12.5 \mathrm{eV}$, respectively) but is sufficient to ionize their complex. This low-energy ionization further reduces the chance of fragmentation of the cation. More importantly, the experimental results of ozone/water concentration depend- ences (see below) indicate that the complex observed at $m / z=$ 66 contains one ozone and one water molecule.

Photolysis Cross-Section. Figure 2 shows the molecular beam intensity profile and laser depletion signal at $248.4 \mathrm{~nm}$ for

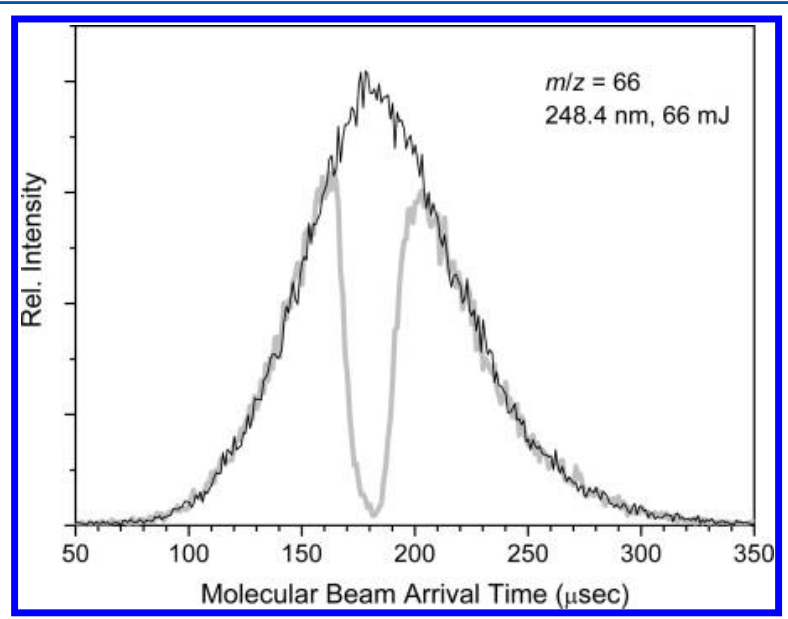

Figure 2. Laser depletion signal of the ozone-water complex $(\mathrm{m} / z=$ 66) at a high laser fluence at $248.4 \mathrm{~nm}$. The thin black line is the molecular beam intensity profile without laser irradiation; the thick gray line is that with laser irradiation.

the ozone-water complex $(m / z=66)$. The absorption crosssection of ozone is quite large $\left(\sim 1 \times 10^{-17} \mathrm{~cm}^{2}\right)$ at this wavelength, ${ }^{34}$ such that the transition could be saturated under this high laser fluence and that most of the molecules in the laser interaction volume were depleted (Supplementary Figure S7). Figure 2 indicates that the ozone-water complex also has a large cross-section at $248.4 \mathrm{~nm}$. Figure $3 \mathrm{~A}$ shows the photodepletion fraction (the number of surviving molecules after laser irradiation divided by the number of molecules without laser irradiation) at an attenuated laser fluence at 248.4 $\mathrm{nm}$. We can see that the ozone-water complex and ozone monomer have similar magnitudes of the photodepletion fractions. Since the probability of photodepletion is proportional to the product of absorption cross-section and quantum yield of the photolysis (the quantum yield is unity in the studied species, see experimental section), similar photodepletion fractions indicate similar absorption cross-sections for the complex and monomer. Further data analysis (see Supporting Information) shows that the cross-section ratio of the ozone-water complex to ozone monomer is $0.99 \pm 0.09$. This result may be well expected, considering that $248.4 \mathrm{~nm}$ is near the peak $(\sim 250 \mathrm{~nm})$ of the broad and intense Hartley band of ozone, and even if there is some spectral shift, it will not cause a large change in the absorption cross-section.

Then, we performed the cross-section measurement at 308.4 $\mathrm{nm}$, which is at the red edge of the Hartley band. Typically, spectral shift would be more obvious at the band edges, but as shown in Figure 3B, we only observed similar photodepletion fractions for the ozone-water complex and ozone monomer, indicating, again, similar cross-sections. Detailed data analysis (see Supporting Information) gives that the cross-section ratio of the complex to ozone is $0.98 \pm 0.10$.

The more important data is the cross-section of the ozonewater complex at $351.8 \mathrm{~nm}$, which lies in the atmospheric window of $\lambda>300 \mathrm{~nm}$, where most tropospheric photochemistry occurs. At $351.8 \mathrm{~nm}$, both ozone and water monomers do not absorb light. To have a comparison base, 


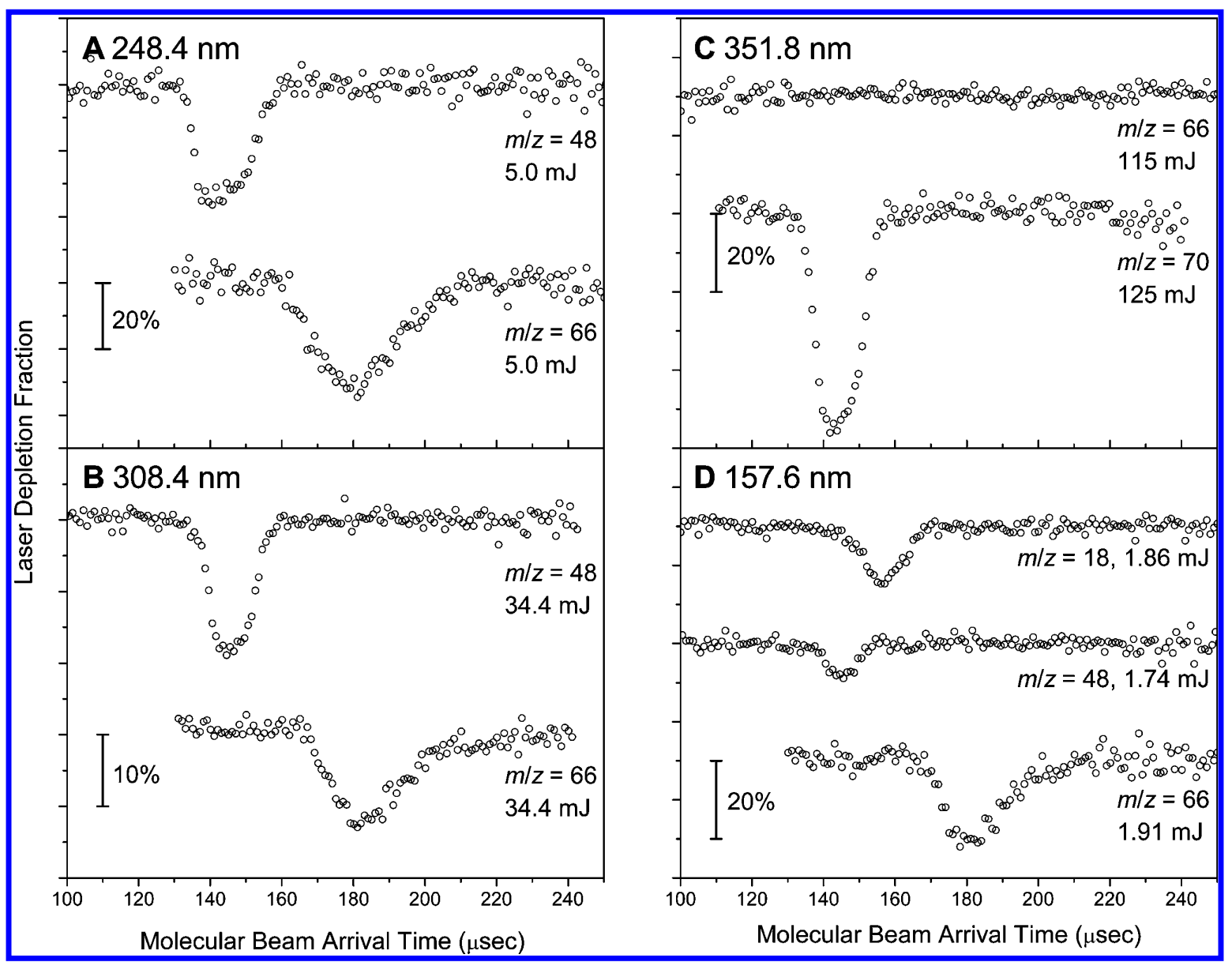

Figure 3. Photodepletion fractions of ozone $(m / z=48)$, water $(m / z=18), \mathrm{Cl}_{2}(m / z=70)$, and the ozone-water complex $(m / z=66)$ at $($ A) 248.4 , (B) 308.4, (C) 351.8, and (D) $157.6 \mathrm{~nm}$. At a given laser wavelength, the laser spot size was the same when detecting different masses.

we performed the measurement for the ozone-water complex and $\mathrm{Cl}_{2}\left(\sigma_{\mathrm{Cl} 2} \approx 1.8 \times 10^{-19} \mathrm{~cm}^{2}\right) .{ }^{34}$ While more than $50 \%$ of the $\mathrm{Cl}_{2}$ molecules could be depleted by the $351.8 \mathrm{~nm}$ laser (Figure 3C), we did not observe any depletion of the ozonewater complex under a similar laser fluence, indicating that the absorption cross-section of the ozone-water complex is much smaller than that of $\mathrm{Cl}_{2}$. Considering the signal-to-noise ratio of our data, we set an upper limit of $0.3 \times 10^{-20} \mathrm{~cm}^{2}$ for the complex cross-section at $351.8 \mathrm{~nm}$ (see the Supporting Information). A summary of the measured cross-section ratios is listed in Table 1.

Since water does not have any significant absorption at the above wavelengths, to probe the water in the complex, we switched the laser wavelength to $157.6 \mathrm{~nm}$ where water has a significant cross-section of $3.55 \times 10^{-18} \mathrm{~cm}^{2}\left(\sigma_{\mathrm{O} 3}=1.6 \times 10^{-18}\right.$ $\mathrm{cm}^{2}$ at $\left.157.6 \mathrm{~nm}\right) .35,36$ In Figure $3 \mathrm{D}$, we can see that the photodepletion fraction of ozone is about half of that of water under similar laser fluences. In the small signal range, the photodepletion fraction is proportional to the cross-section. Thus, this observation is consistent with the cross-section ratio of ozone/water, which is about 1:2. Remarkably, the photodepletion fraction of $m / z=66$ is about 1.5 times that of water, indicating that the cross-section of the ozone-water complex is similar to the sum of the cross-sections of ozone and water.

Ozone/Water Concentration Dependences. We performed cross-section measurements at various ozone concentrations $(0.5-2 \%, \mathrm{v} / \mathrm{v})$ and water concentrations $(0.16-0.88 \%$, $\mathrm{v} / \mathrm{v})$. Within the studied concentration range, the cross-sections
Table 1. Summary of the Cross-Section Measurements of the Ozone-Water Complex $(m / z=66)$

\begin{tabular}{cccc} 
wavelength $(\mathrm{nm})$ & reference molecule & $\begin{array}{c}\sigma_{\text {ref }}(\mathrm{temp}) \\
\left(10^{-20} \mathrm{~cm}^{2}\right)\end{array}$ & $\begin{array}{c}\sigma_{\text {complex }} / \\
\sigma_{\text {ref }}\end{array}$ \\
\hline 157.6 & $\mathrm{H}_{2} \mathrm{O}$ & $355(250 \mathrm{~K})^{a}$ & $1.5^{e}$ \\
& $\mathrm{O}_{3}$ & $160(298 \mathrm{~K})^{b}$ & \\
248.4 & $\mathrm{O}_{3}$ & $1074(218 \mathrm{~K})^{c}$ & $0.99 \pm 0.09^{f}$ \\
308.4 & $\mathrm{O}_{3}$ & $11.5(218 \mathrm{~K})^{c}$ & $0.98 \pm 0.10$ \\
351.8 & $\mathrm{Cl}_{2}$ & $17.95(218 \mathrm{~K})^{c}$ & $<0.018^{g}$ \\
& $\mathrm{O}_{3}$ & $0.0364(298 \mathrm{~K})^{d}$ &
\end{tabular}

${ }^{a} \operatorname{Ref} 35 .{ }^{b} \operatorname{Ref} 36 .{ }^{c} \operatorname{Ref} 34 .{ }^{d} \operatorname{Ref} 37 .{ }^{e}$ Tentative value. ${ }^{f}$ The error bar is for $\pm 1 \sigma$ (one standard deviation) including possible systematic errors. ${ }^{g}$ The upper limit of the complex cross-section at $351.8 \mathrm{~nm}$ is $(17.95 \times$ $\left.10^{-20} \mathrm{~cm}^{2}\right) \times 0.018=0.3 \times 10^{-20} \mathrm{~cm}^{2}$. A significant temperature dependence has been reported for the ozone Huggins bands between 310 and $380 \mathrm{~nm}^{38}$ Our data is referenced to the cross-section of $\mathrm{Cl}_{2}$ which has a much smaller temperature effect. ${ }^{34}$

of the ozone-water complex $(m / z=66)$ at 248.4 and 157.6 $\mathrm{nm}$ do not show any significant change with concentration (see Supporting Information). If both small and large complexes contributed to the observed signal at $m / z=66$, we should see an increase in the cross-section at higher concentrations because larger complexes that have larger cross-sections would be preferably formed at higher concentrations. ${ }^{25}$ Therefore, the experimental results indicate that the species observed at $m / z=66$ contains only one ozone and one water molecule. Moreover, larger complexes that were detected at 
other masses like $m / z=52$ and 82 did show larger crosssections. As mentioned above, the observed ozone-water complex was solvated with Ar atoms, but the number of the Ar atoms cannot be probed in the present experiment because Ar has no absorption at the above laser wavelengths. Nonetheless, the number of the Ar atoms could be increased by increasing the backing pressure, by increasing the valve opening, or by decreasing the ozone concentration (a lower concentration often results in a better cooling). Although we did not perform a systematic investigation on the number of the Ar atoms, we did not observe any change in the complex cross-section due to various degrees of Ar solvation.

Comparison with Previous Work. In Table 1, we can see that the ozone-water complex and ozone have very similar cross-sections at 248.4 and $308.4 \mathrm{~nm}$. This observation indicates that the interaction between ozone and water is not strong enough to affect the absorption process of the complex, similar to the case of ozone dimer. ${ }^{25}$ It also indicates that the Ar solvation does not perturb the absorption of the solute. Remarkably, we did not observe any absorption of the complex at $351.8 \mathrm{~nm}$, contrary to previous suggestions. ${ }^{10-12,16}$ Even our upper limit of $0.3 \times 10^{-20} \mathrm{~cm}^{2}$ for the complex cross-section at $351.8 \mathrm{~nm}$ is still 30 times smaller than the previously estimated value $\left(\sim 1 \times 10^{-19} \mathrm{~cm}^{2}\right.$ at $\left.355 \mathrm{~nm}\right) .{ }^{16}$ The source of this discrepancy is not clear. One possible problem in the previous experiment ${ }^{16}$ might be from the interference of impurity. Ozone aqueous solution is a very strong oxidant, and it might convert some residue chloride salts to chlorine and other chlorine compounds, which might produce $\mathrm{OH}$ radicals after the laser photolysis. However, our results are in line with the experimental absorption spectrum of ozone in aqueous solution, ${ }^{39,40}$ which shows only minor enhancement of the ozone absorption.

With a highly sensitive cavity-enhanced method, Axson et al. $^{22}$ reported the absolute absorption cross-section of ozone at wavelengths of $350-470 \mathrm{~nm}$. They also tried to probe the absorption of the ozone-water complex by comparing the spectra of humidified and dry ozone gases, but they did not observe any change in the absorption spectra. If there is enhancement for the complex absorption in the above wavelength range, they estimated that this enhancement factor should be less than $1 \times 10^{4}$ or $5 \times 10^{2}$, assuming the complex binding energy is 0.7 or $2.4 \mathrm{kcal} \mathrm{mol}^{-1}$, respectively. ${ }^{22}$ Our result at $351.8 \mathrm{~nm}$, however, indicates that the range of the enhancement factor is much smaller, offering a much tighter constraint.

Comparison with Theory. The structure of the ozonewater complex is quite floppy. Recent ab initio calculation ${ }^{17}$ at MP4(SDQ), QCISD, and $\operatorname{CCSD}(\mathrm{T})$ levels indicates the existence of only one stable conformer (double-decker form), while other previously reported conformers (cis, trans, and dipole forms) may be transition states. Nevertheless, the isomerization barriers through the transition states are extremely low, and the authors ${ }^{17}$ also mentioned that the complex will exhibit large amplitude motions and isomerize easily.

For the UV absorption, there are a few theoretical investigations on the electronic excitations of the ozonewater complex, mostly by calculating the vertical excitation energies and oscillator strengths. ${ }^{20,41-43}$ The most recent calculation we found is by Tachikawa and $\mathrm{Abe}^{20}$ using the symmetry adapted cluster and configuration interaction (SAC$\mathrm{CI}$ ) method. Their results suggest that the excitation energy and the oscillator strength for the third excitation (Hartley band) of the complex decrease by a small amount. That is, the absorption spectrum of the ozone-water complex may be slightly red-shifted, but the intensity may be somewhat lower. However, it is hard to obtain any information about the absorption at the band edges with only the vertical excitation energy and oscillator strength. While the theoretical findings of Tachikawa and $\mathrm{Abe}^{20}$ are consistent with this work within possible error bars, we think more complete theoretical treatments including considering the excited-state potential energy surfaces to give a quantitative spectrum may be necessary to provide more insights about this interesting system. It is also important to calculate the effect of conformational structures in the UV absorption spectrum of the ozone-water complex.

Ozone has a significant electron affinity of $2.1 \mathrm{eV} .{ }^{44}$ Thus, it is expected that its hydrated complex may have a chargetransfer transition at much shorter wavelengths $(<225 \mathrm{~nm})$. Although this charge-transfer transition can be strong, it has no relevance to the tropospheric production of $\mathrm{OH}$ radicals from the complex.

Atmospheric Implication. Now we are at a position to reexamine the atmospheric $\mathrm{OH}$ production through the UV photolysis of the ozone-water complex. We may estimate the relative contribution of $\mathrm{OH}$ radicals from the complex UV photolysis (eq 3 ) versus the conventional $\mathrm{OH}$ source (eq 1 and 2) by assuming the following conditions. First, we take the concentrations of ozone, water, and the complex from a typical condition of ref 10 (altitude $=0 \mathrm{~km}$ ). Second, in the conventional $\mathrm{OH}$ source, the ozone photolysis rate coefficient $J$ can be deduced from the solar flux $I$ and the absorption crosssection of ozone $\sigma$; the $\mathrm{O}\left({ }^{1} \mathrm{D}\right)$ production rate coefficient can be obtained by further considering the $\mathrm{O}\left({ }^{1} \mathrm{D}\right)$ quantum yield $\phi\left({ }^{1} \mathrm{D}\right)$ of the ozone photolysis $\left[J=I \sigma ; J\left({ }^{1} \mathrm{D}\right)=I \sigma \phi\left({ }^{1} \mathrm{D}\right)\right]$. Similarly, we can estimate the photolysis rate coefficient of the ozone-water complex by assuming that the complex and the ozone monomer have the same absorption spectra. The resulted wavelength-dependent photolysis and $\mathrm{O}\left({ }^{1} \mathrm{D}\right)$ production rate coefficients are shown in Figure 4. Third, we further

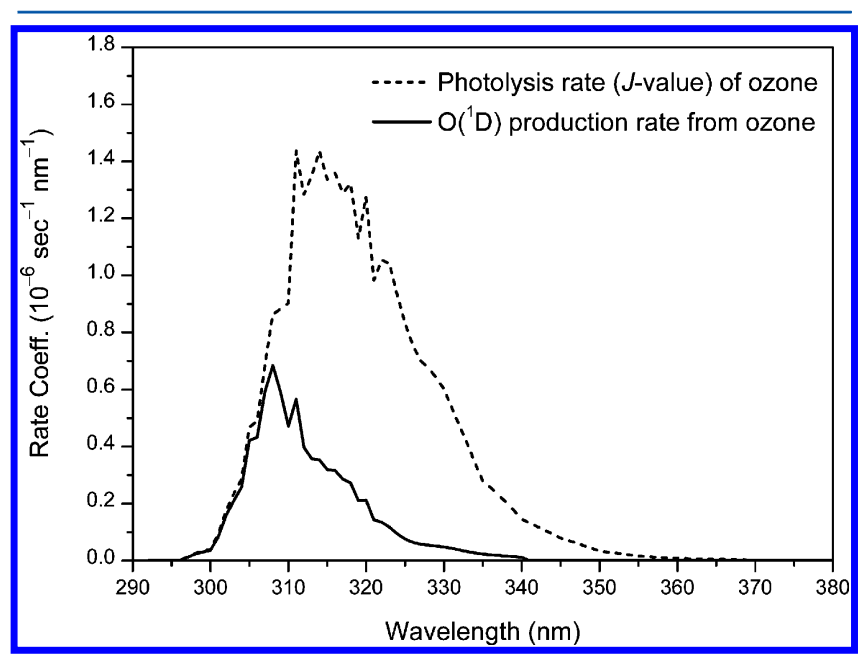

Figure 4. Exemplified wavelength-dependent photolysis and $\mathrm{O}\left({ }^{1} \mathrm{D}\right)$ production rate coefficients of ozone. The absorption cross-section and the $\mathrm{O}\left({ }^{1} \mathrm{D}\right)$ quantum yield of ozone are from the JPL evaluated data. ${ }^{34}$ The solar flux was obtained by using the online NCAR TUV calculator. ${ }^{45}$ Conditions: solar zenith angle $=60^{\circ}$, altitude $=0 \mathrm{~km}$, and stratospheric ozone column density $=300$ Dobson units. 
Table 2. Comparison of the OH Production Rates from the Complex Photolysis and the Conventional OH Source at an Exemplified Condition ${ }^{a}$

\begin{tabular}{|c|c|c|c|c|c|}
\hline & $\operatorname{density}^{a}\left(\mathrm{~cm}^{-3}\right)$ & $J\left({ }^{1} \mathrm{D}\right)$ or $J\left(\sec ^{-1}\right)$ & reaction probability & $\mathrm{OH}$ quantum yield & $\mathrm{OH}$ production rate ${ }^{e}\left(\mathrm{~cm}^{-3} \mathrm{~s}^{-1}\right)$ \\
\hline $\mathrm{O}_{3}$ & $7.5 \times 10^{11}$ & $\left(8.4 \times 10^{-6}\right)^{b}$ & $0.08^{d}$ & 2 & $1.0 \times 10^{6}$ \\
\hline $\mathrm{O}_{3} \cdot \mathrm{H}_{2} \mathrm{O}$ & $<3.7 \times 10^{7}$ & $\left(\sim 3.1 \times 10^{-5}\right)^{c}$ & $\leq 1$ & $\leq 2$ & $\leq 2.3 \times 10^{3}$ \\
\hline
\end{tabular}

${ }^{a}$ For $\left[\mathrm{H}_{2} \mathrm{O}\right]=3.5 \times 10^{17} \mathrm{~cm}^{-3}$ (11 Torr), adapted from the case of $0 \mathrm{~km}$ altitude of ref 10 . Other parameters are the same as those in Figure $4 .{ }^{b}$ The $\mathrm{O}\left({ }^{1} \mathrm{D}\right)$ production rate coefficient $J\left({ }^{1} \mathrm{D}\right)$ from the $\mathrm{O}_{3}$ photolysis, which is the area under the solid line in Figure $4 .{ }^{c}$ The $\mathrm{O}_{3} \cdot \mathrm{H}_{2} \mathrm{O}$ photolysis rate coefficient assumed to be the same as the ozone photolysis rate coefficient $J$, which is the area under the dashed line in Figure $4 .{ }^{d}$ In competition with quenching by $\mathrm{N}_{2}$ and $\mathrm{O}_{2}$; see text. ${ }^{e}$ The $\mathrm{OH}$ production rate is the product of the four numbers listed in the left columns.

consider that the $\mathrm{O}\left({ }^{1} \mathrm{D}\right)$ atoms may be quenched by other species (mostly by $\mathrm{N}_{2}$ and $\mathrm{O}_{2} ; k_{\mathrm{q}}\left(\mathrm{N}_{2}\right)=3.1 \times 10^{-11} \mathrm{~cm}^{3} \mathrm{~s}^{-1}$ and $\left.k_{\mathrm{q}}\left(\mathrm{O}_{2}\right)=4 \times 10^{-11} \mathrm{~cm}^{3} \mathrm{~s}^{-1}\right)^{34}$ before reacting with water $\left(k_{2}=2 \times 10^{-10} \mathrm{~cm}^{3} \mathrm{~s}^{-1}\right){ }^{34}$ Under ambient conditions, the probability of converting $\mathrm{O}\left({ }^{1} \mathrm{D}\right)$ atoms to $\mathrm{OH}$ radicals (eq 2) largely depends on the humidity; it ranges roughly from $4 \%$ to $18 \%$ (for $\mathrm{H}_{2} \mathrm{O}$ partial pressure $=5-25$ Torr; total pressure $=$ 760 Torr). However, we assume that the $\mathrm{OH}$ quantum yield of the complex photolysis is 2 at wavelengths between 200-400 $\mathrm{nm}$. It is important to note that this value may be reduced if $\mathrm{O}\left({ }^{3} \mathrm{P}\right)$ atom is produced from the complex photolysis $\left(\mathrm{O}_{3} \cdot \mathrm{H}_{2} \mathrm{O}\right.$ $\left.+h \nu \rightarrow \mathrm{O}\left({ }^{3} \mathrm{P}\right)+\mathrm{O}_{2}+\mathrm{H}_{2} \mathrm{O}\right)$, which is quite likely especially at longer wavelengths.

The parameters and calculated $\mathrm{OH}$ production rates are given in Table 2. Under the chosen condition, the estimated $\mathrm{OH}$ production rate from the complex photolysis is insignificant. At larger solar zenith angles, the relative $\mathrm{OH}$ contribution from the complex photolysis may increase slightly because the $\mathrm{OH}$ production from the conventional source would be reduced by a larger amount (mainly due to the decrease of $\phi\left({ }^{1} \mathrm{D}\right)$ beyond $310 \mathrm{~nm}$ and the more red-shifted solar spectra), but the maximum complex contribution is still less than one percent in comparison with the conventional $\mathrm{OH}$ source. Finally, we like to emphasize that the $\mathrm{OH}$ quantum yield of the complex photolysis is unknown and should be wavelength dependent (that is, it is possible that the $\mathrm{OH}$ quantum yield is smaller than 2).

\section{CONCLUDING REMARKS}

The absorption cross-section of the ozone-water complex has been determined at a few wavelengths relevant to the atmosphere. This complex was selectively probed by means of argon solvation, tunable vacuum UV photoionization, and mass-resolved detection. At 248.4 and $308.4 \mathrm{~nm}$, the complex and ozone monomer have similar absorption cross-sections. At $351.8 \mathrm{~nm}$, the complex cross-section is too small to be measured; a much tighter upper limit of $0.3 \times 10^{-20} \mathrm{~cm}^{2}$ has been determined for the complex absorption cross-section.

The atmospheric $\mathrm{OH}$ production through the complex photolysis can be reevaluated based on the new information about the absorption cross-section of the ozone-water complex. Even under favorable situations, the contribution of $\mathrm{OH}$ from the complex photolysis would be insignificant with respect to the conventional $\mathrm{OH}$ source.

Finally, it is worth mentioning that the methods we made use of in this study are not limited to the ozone-water complex. The Ar resonance at $12 \mathrm{eV}$ lies just in a suitable energy range for soft ionizing water-related complexes (considering $\mathrm{IE}_{\mathrm{H} 2 \mathrm{O}}=$ $12.6 \mathrm{eV}$, if the energy is too high, dissociative ionization becomes very probable; if the energy is too low, the ionization yield may be low). In summary, we have demonstrated an efficient method to selectively probe the ozone-water complex and have determined its UV absorption cross-sections, which would provide a new constraint on the atmospheric photolysis rates of the ozone-water complex.

\section{ASSOCIATED CONTENT}

\section{Supporting Information}

Detailed experimental procedures, method, data analysis, and experimental results. This material is available free of charge via the Internet at http://pubs.acs.org.

\section{AUTHOR INFORMATION}

\section{Corresponding Author}

*Tel: +886-2-2366-8258. Fax: +886-2-2362-0200. E-mail: jimlin@gate.sinica.edu.tw.

\section{Notes}

The authors declare no competing financial interest.

\section{ACKNOWLEDGMENTS}

This work was supported by Academia Sinica and the National Science Council of Taiwan (NSC 100-2113-M-001-008-MY3). The authors thank Dr. K. Takahashi and Professor Y. T. Lee for valuable comments.

\section{REFERENCES}

(1) Domine, F.; Shepson, P. B. Science 2002, 297, 1506-1510.

(2) Li, S. P.; Matthews, J.; Sinha, A. Science 2008, 319, 1657-1660.

(3) Matthews, J.; Sinha, A.; Francisco, J. S. Proc. Natl. Acad. Sci. 2005, $102,7449-7452$.

(4) Su, H.; Cheng, Y. F.; Oswald, R.; Behrendt, T.; Trebs, I.; Meixner, F. X.; Andreae, M. O.; Cheng, P.; Zhang, Y.; Poschl, U. Science 2011, 333, 1616-1618.

(5) Taraborrelli, D.; Lawrence, M. G.; Crowley, J. N.; Dillon, T. J.; Gromov, S.; Gross, C. B. M.; Vereecken, L.; Lelieveld, J. Nat. Geosci. 2012, 5, 190-193.

(6) Di Carlo, P.; Brune, W. H.; Martinez, M.; Harder, H.; Lesher, R.; Ren, X. R.; Thornberry, T.; Carroll, M. A.; Young, V.; Shepson, P. B.; et al. Science 2004, 304, 722-725.

(7) Hofzumahaus, A.; Rohrer, F.; Lu, K. D.; Bohn, B.; Brauers, T.; Chang, C. C.; Fuchs, H.; Holland, F.; Kita, K.; Kondo, Y.; et al. Science 2009, 324, 1702-1704.

(8) Wennberg, P. O.; Salawitch, R. J.; Donaldson, D. J.; Hanisco, T. F.; Lanzendorf, E. J.; Perkins, K. K.; Lloyd, S. A.; Vaida, V.; Gao, R. S.; Hintsa, E. J.; Cohen, R. C.; et al. Geophys. Res. Lett. 1999, 26, 13731376.

(9) Wennberg, P. O.; Dabdub, D. Science 2008, 319, 1624-1625.

(10) Frost, G.; Vaida, V. J. Geophys. Res., [Atmos.] 1995, 100, 1880318809.

(11) Vaida, V.; Kjaergaard, H. G.; Feierabend, K. J. Int. Rev. Phys. Chem. 2003, 22, 203-219.

(12) Vaida, V. J. Chem. Phys. 2011, 135, 020901.

(13) Vaida, V.; Headrick, J. E. J. Phys. Chem. A 2000, 104, 54015412.

(14) Sennikov, P. G.; Ignatov, S. K.; Schrems, O. ChemPhysChem 2005, 6, 392-412. 
(15) Vohringer-Martinez, E.; Hansmann, B.; Hernandez, H.; Francisco, J. S.; Troe, J.; Abel, B. Science 2007, 315, 497-501.

(16) Hurwitz, Y.; Naaman, R. J. Chem. Phys. 1995, 102, 1941-1943.

(17) Tsuge, M.; Tsuji, K.; Kawai, A.; Shibuya, K. J. Phys. Chem. A 2007, 111, 3540-3547.

(18) Gillies, J. Z.; Gillies, C. W.; Suenram, R. D.; Lovas, F. J.; Schmidt, T.; Cremer, D. J. Mol. Spectrosc. 1991, 146, 493-512.

(19) Schriver, L.; Barreau, C.; Schriver, A. Chem. Phys. 1990, 140, 429-438.

(20) Tachikawa, H.; Abe, S. Chem. Phys. Lett. 2006, 432, 409-413.

(21) King, D. S.; Sauder, D. G.; Casassa, M. P. J. Chem. Phys. 1994, 100, 4200-4210.

(22) Axson, J. L.; Washenfelder, R. A.; Kahan, T. F.; Young, C. J.; Vaida, V.; Brown, S. S. Atmos. Chem. Phys. 2011, 11, 10.

(23) Buckley, P. T.; Birks, J. W. Atmos. Environ. 1995, 29, 24092415 .

(24) Chen, H. Y.; Lien, C. Y.; Lin, W. Y.; Lee, Y. T.; Lin, J. J. Science 2009, 324, 781-784.

(25) Chen, I.-C.; Chen, A. F.; Huang, W.-T.; Takahashi, K.; Lin, J. J. Chem.-Asian J. 2011, 6, 2925.

(26) Jin, B.; Chen, I. C.; Huang, W. T.; Lien, C. Y.; Guchhait, N.; Lin,

J. J. J. Phys. Chem. A 2010, 114, 4791-4797.

(27) Lien, C. Y.; Lin, W. Y.; Chen, H. Y.; Huang, W. T.; Jin, B.; Chen, I. C.; Lin, J. J. J. Chem. Phys. 2009, 131, 174301.

(28) Lin, J. J.; Chen, A. F.; Lee, Y. T. Chem.-Asian J. 2011, 6, 16641678.

(29) Lee, S. H.; Lin, J. J.; Lee, Y. T. J. Electron Spectrosc. Relat. Phenom. 2005, 144, 135-138.

(30) Lin, J. J.; Chen, Y.; Lee, Y. Y.; Lee, Y. T.; Yang, X. M. Chem. Phys. Lett. 2002, 361, 374-382.

(31) Even, U.; Jortner, J.; Noy, D.; Lavie, N.; Cossart-Magos, C. J. Chem. Phys. 2000, 112, 8068-8071.

(32) Hillenkamp, M.; Keinan, S.; Even, U. J. Chem. Phys. 2003, 118, 8699-8705.

(33) Golan, A.; Ahmed, M. J. Phys. Chem. Lett. 2012, 3, 458-462.

(34) Sander, S. P.; Friedl, R. R.; Abbatt, J. P. D.; Barker, J. R.; Burkholder, J. B.; Golden, D. M.; Kolb, C. E.; Kurylo, M. J.; Moortgat, G. K.; Wine, P. H.; et al. Chemical Kinetics and Photochemical Data for Use in Atmospheric Studies 10-6; Jet Propulsion Laboratory: Pasadena, CA, 2011.

(35) Chung, C. Y.; Chew, E. P.; Cheng, B. M.; Bahou, M.; Lee, Y. P. Nucl. Instrum. Methods Phys. Res., Sect. A 2001, 467, 1572-1576.

(36) Ackerman, M. Ultraviolet Solar Radiation Related to Mesospheric Processes; Astrophysics and Space Science Library; Springer: New York, 1971; Vol. 25, p 149.

(37) Chen, J.; Venables, D. S. Atmos. Meas. Tech. 2011, 4, 425-436.

(38) Voigt, S.; Orphal, J.; Bogumil, K.; Burrows, J. P. J. Photochem. Photobiol., A 2002, 143, 1-9.

(39) Hart, E. J.; Sehested, K.; Holcman, J. Anal. Chem. 1983, 55, 4649.

(40) Taube, H. Trans. Faraday Soc. 1957, 53, 656-665.

(41) Tachikawa, H.; Abe, S. Inorg. Chem. 2003, 42, 2188-2190.

(42) Tachikawa, H.; Abe, S. Inorg. Chim. Acta 2005, 358, 288-294.

(43) Staikova, M.; Donaldson, D. J. Phys. Chem. Earth, Part C 2001, 26, 473-478.

(44) Arnold, D. W.; Xu, C. S.; Kim, E. H.; Neumark, D. M. J. Chem. Phys. 1994, 101, 912-922.

(45) NCAR Tropospheric Ultraviolet and Visible (TUV) Calculator, available at http://cprm.acd.ucar.edu/Models/TUV/Interactive $\mathrm{TUV} /$. 